\title{
Time-Resolved X-ray Absorption Spectroscopy in (Photo)Electrochemistry
}

\author{
Martina Fracchia ${ }^{1}$, Paolo Ghigna ${ }^{1}\left(\mathbb{D}\right.$, Alberto Vertova ${ }^{2}$, Sandra Rondinini ${ }^{2}$ and \\ Alessandro Minguzzi $2, *$ (D) \\ 1 Dipartimento di Chimica, Università degli Studi di Pavia, Viale Taramelli 13, 27100 Pavia, Italy; \\ martina.fracchia02@universitadipavia.it (M.F.); paolo.ghigna@unipv.it (P.G.) \\ 2 Laboratory of Applied Electrochemistry, Dipartimento di Chimica, Università degli Studi di Milano, \\ Via Golgi 19, 20133 Milano, Italy; alberto.vertova@unimi.it (A.V.); sandra.rondinini@unimi.it (S.R.) \\ * Correspondence: alessandro.minguzzi@unimi.it; Tel.: +39-025-0314-224
}

Received: 7 November 2018; Accepted: 1 December 2018; Published: 5 December 2018

\begin{abstract}
This minireview aims at providing a complete survey concerning the use of X-ray absorption spectroscopy (XAS) for time-resolved studies of electrochemical and photoelectrochemical phenomena. We will see that time resolution can range from the femto-picosecond to the second (or more) scale and that this joins the valuable throughput typical of XAS, which allows for determining the oxidation state of the investigated element, together with its local structure. We will analyze four different techniques that use different approaches to exploit the in real time capabilities of XAS. These are quick-XAS, energy dispersive XAS, pump \& probe XAS and fixed-energy X-ray absorption voltammetry. In the conclusions, we will analyze possible future perspectives for these techniques.
\end{abstract}

Keywords: X-ray absorption spectroscopy; energy dispersive; quick-XAS; FEXRAV; free electron laser; electrochemistry; photoelectrochemistry; photochemistry; pump \& probe

\section{Introduction}

The research of efficient materials in chemistry and physics requires new criteria for their rational design and thus the definition of new paradigms for the elucidation of structureperformance guidelines.

In catalysis, the investigation on reaction mechanisms and on the concomitant changes in the catalyst nature becomes therefore crucial. Thus, the quest for analytical tools capable of directly detecting any information on the reactant-intermediate-product sequence and on the catalyst role in the course of the reaction is imperative.

In this respect, operando spectroscopies are obviously central, since they can assume the role of an independent, uncoupled source of information with respect to the primary ones (such as products yield, selectivity, or potential/current characteristics in the case of electrochemistry).

In the recent past, consequently, a flourishing use of operando spectroscopies in the study of electrochemical and photoelectrochemical phenomena has emerged, particularly within the framework of energy and environmental applications [1,2].

Among the different spectroscopic techniques, X-ray absorption (XAS) is particularly attractive being able to provides a particularly complete picture of the system of interest. In fact, and despite the need of large-scale synchrotron radiation facilities, it provides fundamental information on the local electronic and atomic structure of a selected element. Indeed, the latter characteristic is one of the most intriguing for XAS: tuning the energy of the incident X-ray beam, it is possible to select the 
element under consideration. This is vital for operando experiments, since the spectroscopic response is independent on any element in the beam different from that under investigation.

Another enabling feature of XAS is the high energy of X-rays: especially in the so-called "hard" X-ray regime (roughly, with energies higher than $8-10 \mathrm{keV}$ ), the absorption by all light elements (e.g., $\mathrm{C}, \mathrm{H}, \mathrm{O}, \mathrm{N}$ ) is negligible. Thus, most of the electrolytes adopted in electrochemistry as well as selected cell materials (especially if polymer-based) are transparent, and therefore operando studies are quite undemanding.

The principles of X-ray absorption spectroscopy can be briefly described as follows. When an $\mathrm{X}$-ray photon with proper energy is shined over a sample, it can excite a core electron. Core electrons are in localized states, the energy of which is almost independent of the chemical environment. This is the reason for which XAS is element selective. At energy corresponding to the binding energy of the core level, the absorption coefficient has an abrupt change, called absorption edge. The excited electron can be promoted either to unoccupied bound levels or to continuum unbound levels, as pictorially described in Figure 1.

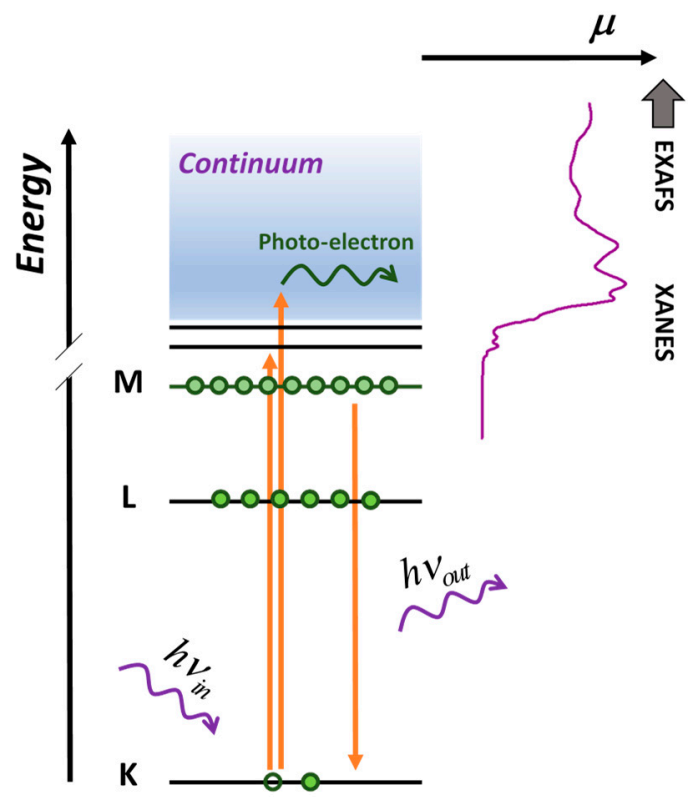

Figure 1. Scheme of the excitation and de-excitation processes involved in X-ray absorption spectroscopy (XAS). An X-ray photon $\left(h v_{\text {in }}\right)$ can promote a core electron either to bound or continuum empty states. Transitions to bound states result into spectral features in the X-ray Absorption Near Edge Structure (XANES) region, while transitions to continuum states give rise to the Extended X-ray Absorption Fine Structure (EXAFS) oscillations. Radiative de-excitation processes result into X-rays fluorescence lines $\left(h v_{\text {out }}\right)$. Core levels in the figure are named according to the Sommerfeld notation.

In this case, it can be back-diffused (scattered) by surrounding atoms. For a given photon energy, the interaction between the emitted electron and back-scattered waves can be destructive or constructive depending on the interatomic distance. This effect leads to an oscillation of the absorption coefficient for X-ray energy, extending to several hundreds of eV above the absorption edge. This is the so-called Extended X-ray Absorption Fine Structure (EXAFS), and allows for determining the local structure (number, nature and distance of surrounding atoms) around the photoabsorber. At energies close to the edge, the absorption coefficient has very strong modulations. This is the X-ray Absorption Near Edge Structure (XANES), that is due to electronic transitions to bound unoccupied states, and/or by multiple scattering events. XANES gives important information on the coordination environment (type of coordination and its distortions). Finally, the exact energy at which the absorption edge falls finely depends on the electron density on the photoabsorber, and thus reflects the oxidation state. Therefore, XAS gives an independent determination of the oxidation state of atoms in compounds. 
Time resolved spectroscopies are of fundamental importance in studying the kinetics and dynamics of chemical reactions. With the introduction of third generation synchrotrons and, more recently, of free-electron lasers, time-revolved XAS became accessible thanks to the extremely high photon flux that can be impinged on the sample.

Time-resolved XAS include different techniques that allow spanning between picoseconds/ femtoseconds and seconds/hours timescales, thus permitting the study of a wide range of phenomena, from the formation of photogenerated charges to charge transfers, from reaction mechanisms to slowly activity-losing systems.

In this review, we aim at summarizing the most important contributions achieved so far in the use of time-resolved XAS in electrochemistry and photoelectrochemistry.

For a more comprehensive, extended and didactic source of information, the Reader is invited to consider a recent book chapter [3] and earlier reviews [4-6].

Here we recall the fact that XAS is a bulk technique and averages on all atoms in the beam. However, a proper sample choice allows being sensitive to surface atoms: the most adopted strategies are (i) the study of small nanoparticles, where the surface/bulk atom ratio is particularly high and (ii) the use of "bulk active" materials. A classic example of the last case are hydrous oxides where, up to a certain load, all atoms (external surface and bulk) are addressable by charged and uncharged species from/to the electrolyte, thus being in the condition to act as active sites [7].

For what concerns the different strategies that can be adopted for time resolved experiment, we need to consider all variables that are into play: X-ray energy, $\mathrm{X}$-ray absorption coefficient, applied potential (or scan rate, if in coupling with electrochemical methods), presence/absence of illumination and, obviously, time.

The most obvious approach is to record full XAS spectra at different times. This leads us to discuss: quick-XAS, energy dispersive XAS and pump \& probe XAS.

\section{Quick-XAS}

Usually, an XAS spectrum is recorded by stepping the monochromator and counting each point for a relatively long time, typically in the order of seconds or several seconds. In the quick-XAS approach, the monochromator is continuously moved over an energy interval and the absorption coefficient, $\mu$, is continuously measured. In this way, a typical XANES spectrum can be recorded in few seconds or even in less than a second [8-11]. One of the very first examples of fast acquisition using a quick-XAS approach is reported in Figure 2.

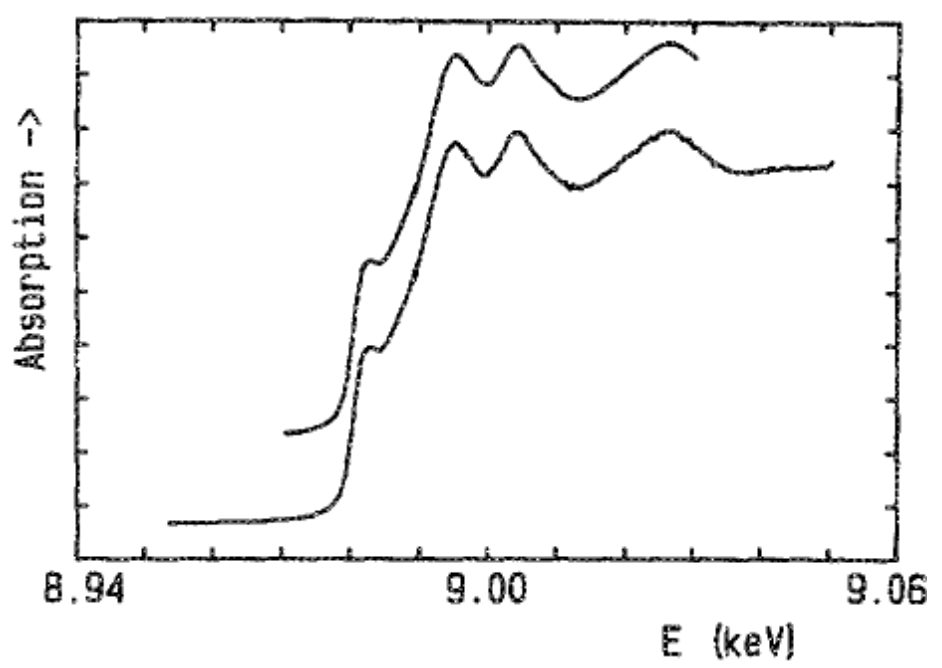

Figure 2. Cu-K edge spectra of a metal foil at room temperature measured in $72 \mathrm{~s}$ using a "conventional" step-by-step scan (upper spectrum) and in $6 \mathrm{~s}$ using the quick-XAS approach (lower spectrum. Reprinted from [9], with the permission of AIP Publishing. 
Quick XAS has been largely employed in electrochemistry for dynamic studies in energy storage systems. For example, Yu et al. monitored the electrochemical delithiation of $\mathrm{LiFePO}_{4}$, a well-known cathode material in lithium batteries, by exploiting the capability of XANES to easily distinguish between the $\mathrm{LiFePO}_{4}$ and the $\mathrm{FePO}_{4}$ phases [12]. They found that the delithiation proceeds with a "two-phase reaction", in agreement with other works in the literature. In addition, assuming that the kinetic is limited by lithium diffusion, the authors could estimate an apparent $\mathrm{Li}^{+}$diffusion coefficient of $1.9 \times 10^{-13} \mathrm{~cm}^{2} \cdot \mathrm{s}^{-1}$.

Ishiguro et al. monitored surface events occurring on a $\mathrm{Pt}_{3} \mathrm{Co} / \mathrm{C}$ cathode catalyst in proton exchange membrane fuel cell (PEMFC), with a time resolution of $500 \mathrm{~ms}$ [13]. With quick XAS (acquired both at the $\mathrm{Pt}_{\mathrm{III}}{ }^{-}$and the Co K-edges) they could achieve a complete understanding of the structural and electronic changes occurring in this material during the fuel-cell operating processes. In addition, they compared the reaction mechanism of $\mathrm{Pt}_{3} \mathrm{Co} / \mathrm{C}$ with that of $\mathrm{Pt} / \mathrm{C}$ catalyst. They found that while the two catalysts have similar reactions mechanisms, large increases in the rate constants are observed when Co is added to Pt.

Quick XAS has been employed in the study of electrocatalysts for various reactions, like Hydrogen Evolution Reaction (HER), Oxygen Evolution Reaction (OER) or Oxygen Reduction Reaction (ORR). The aim is to assess the effective chemical nature of an electrocatalyst under working conditions. An example is the work by Gorlin Y. et al., where a bifunctional manganese oxide $\left(\mathrm{MnO}_{\mathrm{x}}\right)$ was studied as catalyst for both OER and ORR reactions [14]. At a potential value of $0.7 \mathrm{~V}$ vs. RHE, where the ORR takes place, a disordered $\mathrm{Mn}(\mathrm{II}, \mathrm{III}) \mathrm{O}_{4}$ spinel is found. When the potential is increased at $1.8 \mathrm{~V}$, relevant to the OER, $80 \%$ of the film is oxidized to $\mathrm{Mn}(\mathrm{III}, \mathrm{IV})$ oxide, while the remaining part consists of $\mathrm{Mn}(\mathrm{II}, \mathrm{III}) \mathrm{O}_{4}$, thus suggesting that a $\mathrm{Mn}(\mathrm{III}, \mathrm{IV})$ oxide is the actual responsible for the OER. As quick XAS cannot reach the $m s$ timescale, the authors could not provide any insight into the dynamics of the process. However, they were able to prove that the catalyst reached a stationary condition at all the potentials under investigation.

\section{Energy Dispersive XAS}

While the quick-XAS approach opens the way to time-resolved XAS, the sub-second timescale is not accessible, thus hindering the study of fast chemical reaction. In the energy dispersive approach, an XAS spectrum can be obtained in a timescale of milliseconds, which is quite satisfactory for a large part of fast chemical phenomena. In a dispersive XAS beamline, a bent monochromator is used to focus a polychromatic (pink) beam on the sample. The beam then diverges after the sample and the different wavelengths are spatially separated. A position sensitive detector placed after the sample is therefore used to acquire the spectrum. Examples of the use of energy dispersive XAS (EDXAS) in electrochemistry date back to late 1980s and early 1990s [15,16]. However, only after the introduction of fast and linear detectors [17] it was possible to reach the sub-second timescale. Since then, the technique has evolved into a powerful tool to investigate fast chemical phenomena [18-20]. From what concerns electrochemistry, EDXAS was employed to monitor the dynamics of oxidation and reduction on electrodes for different applications. In a seminal experiment in 1989, EDXAS was coupled to cyclic voltammetry to investigate the XANES at the Ni K-edge in $\alpha-\mathrm{Ni}(\mathrm{OH})_{2}$ and $\beta-\mathrm{Ni}(\mathrm{OH})_{2}$ in $\mathrm{KOH}$ [16]. A continuous shift to higher values of the edge energy position was observed in concomitance with the oxidation from $\mathrm{Ni}(\mathrm{II})$ to $\mathrm{Ni}(\mathrm{III})$ and, at the same time, a change in the spectral profile related to a distortion of the octahedral coordination of the six oxygen atoms surrounding Ni was detected.

Rose et al. investigated the kinetics of the electrochemical formation of palladium $\beta$-hydride and $\beta$-deuteride in carbon-supported Pd catalyst nanoparticles [21]. The rate determining step of the formation of $\beta$-hydride was found to be the diffusion of $\mathrm{H}$ through the bulk of the Pd particles; in case of $\beta$-deuteride, the authors observed that the reaction was limited by the interfacial reduction of $\mathrm{D}^{+}$. In addition, they were able to determine in both cases the stoichiometry of the two phases.

It has to be noted that EDXAS can also be employed to study time-resolved processes occurring in solution, particularly in the immediate proximity of the electrode. As an example, $\mathrm{O}^{\prime}$ Malley et al. 
considered the electrodesorption of copper on a platinum electrode in order to study the diffusion of $\mathrm{Cu}^{2+}$ ions as a function of time and distance from the electrode surface [22].

Great effort has been devoted in the recent years to investigate the electrochemical behavior of Pt-based electrodes. Allen et al. investigated both the oxidation and reduction of dispersed Pt catalyst, studying in real time the modifications of the Pt oxidation state and of the number of $\mathrm{O}$ and Pt nearest neighbors [15]. Moreover, they found evidences for a different mechanism of oxidation/reduction in case of clusters with respect to bulk electrodes. In another paper, the same authors describe the use of EDXAS to record full XAS spectra while the electrode potential follows a cyclic voltammetric profile [23]. This approach allowed for determining structural parameters (such as the average coordination number of $\mathrm{Pt}$ and $\mathrm{O}$ atoms around $\mathrm{Pt}$ ) as a function of the applied potential. This, in turn, allowed for distinguishing between oxygen adsorbing in the double-layer region from the Pt oxidation that is typically observed in CV at higher potentials.

The electrochemical oxidation of the surfaces of Pt nanoparticles was further investigated by Imai et al. with a sub-second time resolution [24]. As shown in Figure 3, after applying a potential of $1.4 \mathrm{~V}$ vs. RHE in acidic media, they exploited the high sensitivity of the EXAFS region towards the local Pt-Pt and Pt-O distances, to monitor their change in time.
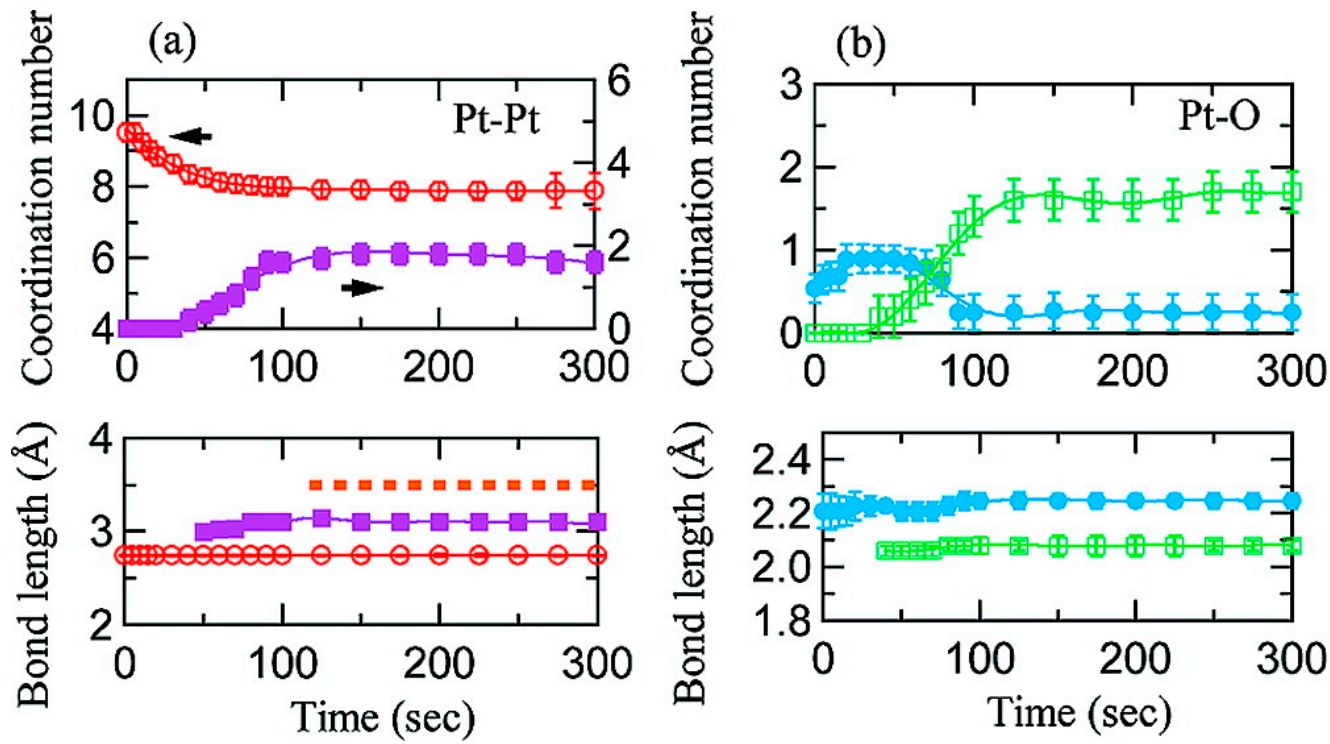

Figure 3. Example of outcome from an operando energy dispersive-XAS experiments on $\mathrm{Pt}$ nanoparticles. Bond lengths and coordination numbers as a function of time for (a) Pt-Pt and (b) Pt-O bonds during potential step at $1.4 \mathrm{~V}$. In (a), it is possible to observe Pt-Pt bonds with $2.7 \AA$ (metallic platinum) plus two types of longer Pt-Pt bonds (Pt-Pt bonds in platinum oxides, 3.1 and $3.5 \AA$ ), the latter appearing at about 40 and 100-120 s, respectively. In (b), longer Pt-O bonds (due adsorbed oxygen species) turn into shorter Pt-O (Pt-O bonds in oxides). Reprinted with permission [24]. Copyright 2009 American Chemical Society.

The authors found that longer Pt-O bonds are initially formed, indicating the formation of $\mathrm{Pt}-\mathrm{OHH}$ and/or Pt-OH species; afterwards, these species turn to shorter Pt-O bonds, and the formation of $\alpha-\mathrm{PtO}_{2}$ was detected. Finally, after $100 \mathrm{~s}$, a precursor of $\beta-\mathrm{PtO}_{2}$ is formed.

EDAXS was also used to study the oxidation of $\mathrm{Pt}$ nanoparticles in presence of competing halide ions $\left(\mathrm{Cl}^{-}\right.$and $\left.\mathrm{Br}^{-}\right)$[25]. The kinetic parameters obtained by the time resolved experiment confirmed the two step model proposed by Zolfaghari, Conway and Jerkiewicz [26]. As evident from Figure 4, the competing effect of the halides was found to be significant mainly on the first step. In addition, the partial discrepancy, particularly at short times, between the integrated quantity of charge and the occupancy of $\mathrm{Pt} 5 d$ states obtained by XAS suggests a non-negligible role of anion redox activity. 

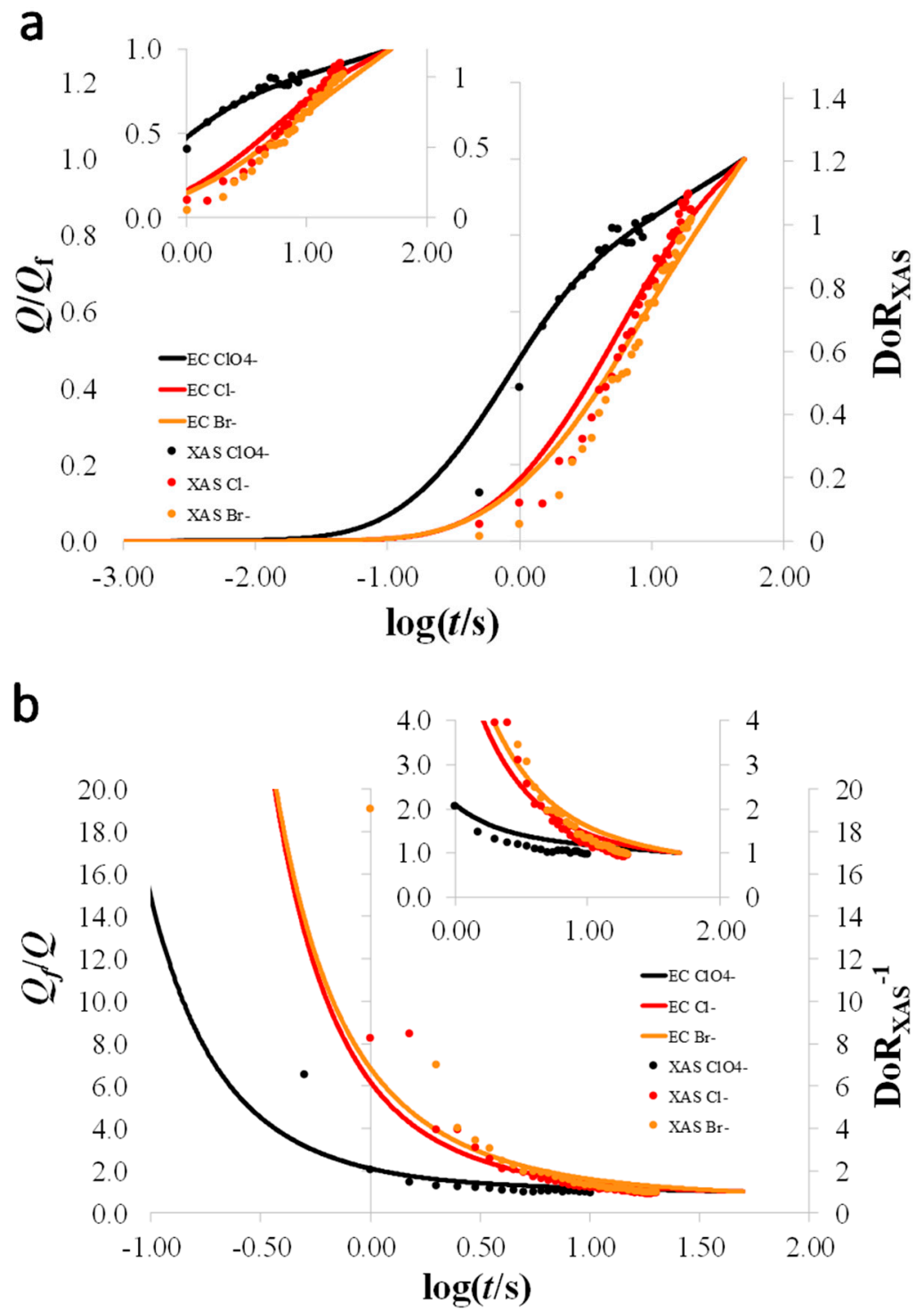

Figure 4. IR corrected results for operando ED-XAS in the case of Pt nanoparticles oxidation (and the relevant following reduction) in aqueous in $0.1 \mathrm{M} \mathrm{HClO}_{4}$ (black), $0.1 \mathrm{M} \mathrm{HClO}_{4}+10 \mathrm{mM} \mathrm{KCl}$ (red) and $0.1 \mathrm{M} \mathrm{HClO}_{4}+10 \mathrm{mM} \mathrm{KBr}$ (orange). (a) $Q / Q f$ (full lines) and Degree of reaction (DoR, by XAS) (dots) and $(\mathbf{b})\left(Q / Q_{\mathrm{f}}\right)^{-1}$ (full lines) and DoRXAS ${ }^{-1}$ (dots) as a function of $\log (t)$ for a 0.5 e $1.4 \mathrm{~V}$ (reversible hydrogen electrode) step. Reprinted from [25]. Copyright 2018, with permission from Elsevier.

The oxidation and reduction of highly hydrated $\mathrm{IrO}_{x}$, one of the most active electrocatalysts for OER, was recently investigated by EDXAS [27]. The complementary information between XAS and chronoamperometry evidenced parasitic and side reactions. In addition, the role and time evolution of hydration degree and persistence of iridium in different charge states was discussed.

Finally, a very recent paper discussed the stability of the copper(II) lactate complex in alkaline solution, used as a precursor for the electrodeposition of $\mathrm{Cu}_{2} \mathrm{O}$, finding that the complex is stable in a wide range of applied potentials [28]. The authors were also able to determine the structure of the complex in solution by fitting the XANES data.

\section{Pump \& Probe XAS}

This method can be applied in photochemistry or in photoelectrochemistry. It consists in exciting the system with photons of desired energy ("pump", typically in the visible or in the UV range) before probing the system with X-ray photons. The X-ray beam from a synchrotron radiation source has a 
characteristic time pattern that reflects the pattern of the electron bunches in the storage ring. The sub- $\mu$ s timescale is then achievable with this approach. The probe is delayed with respect to the pump in dependence on the timescale of the phenomena under investigation. This is evident in the study of photochemistry, where pump \& probe XAS was initially used instead of time-resolved X-ray diffraction to have structural information on disordered or dissolved species [29]. The technique was recently used to probe the charge carrier dynamics in semiconductors used as photocatalysts, such as $\mathrm{TiO}_{2}$ and $\mathrm{WO}_{3}$, as discussed in the following.

In the case of $\mathrm{TiO}_{2}$, thanks to picosecond XAS, Rittmann and co-workers performed an experiment at the Ti K-edge and the Ru $\mathrm{L}_{\mathrm{III}}$-edge to study the lifetime of photogenerated trapped electrons for photoexcited bare and N719-dye-sensitized anatase and amorphous $\mathrm{TiO}_{2}$ nanoparticles [30]. The outcomes point to the existence of different types of defects (either at the surface or in the bulk) in dependence on the type of particles and on the presence/absence of the dye. In case of dye-sensitized anatase or amorphous $\mathrm{TiO}_{2}$ they could observe the formation of $\mathrm{Ti}^{3+}$ defects in trapping sites that are pentacoordinated, i.e. defective, meaning that the trapping center is localized at the outer surface of the crystallite. The trap lifetime is in the order of nanoseconds. This is a typical result possible only with XAS, which, being element-specific, allows for obtaining a direct information on the electronic and local structure of Ti.

Pump \& probe XAS was also used in photochemistry and photoelectrochemistry to investigate different metal complexes, especially in the fields of energy storage and conversion. Many literature works concern the usage of Cobalt-based complexes as water oxidation or water reduction catalysts for artificial photosynthesis. In a work by Song et al. two cubane-like catalysts for water oxidation were investigated through in situ XANES under photocatalytic conditions: it was observed that the $\left\{\mathrm{Co}(\mathrm{II})_{4} \mathrm{O}_{4}\right\}$ core undergoes a rapid oxidation from $\mathrm{Co}(\mathrm{II})$ to $\mathrm{Co}(\mathrm{III})$ or higher valent states, and then $\mathrm{Co}(\mathrm{II})$ is slowly restored [31]. Moonshiram and co-workers investigated through transient XAS the electronic and structural dynamics of $\left[\mathrm{Ru}(\mathrm{bpy})_{3}\right]^{2+} /\left[\mathrm{LCo}\left(\mathrm{III}^{2} \mathrm{Cl}_{2}\right]^{+}\right.$hybrid systems used as catalysts for water reduction in the photosplitting of water [32]. When the chromophore is excited, the cobalt (III) octahedral complex is reduced to Co(II). In addition, they repeated the experiment in the presence of sodium ascorbate/ascorbic acid electron donor, finding the experimental proof of the formation of a $\mathrm{Co}(\mathrm{I})$ square planar species, followed by the formation of the octahedral $\mathrm{Co}$ (III) starting complex with two aquo-ligands.

Canton et al. employed ultrafast optical and X-ray techniques (coupled to DFT calculations) to identify the light-induced electron transfer and the associated structural and spin changes occurring in two photoexcited heterobimetallic ruthenium-cobalt complexes [33].

The quest for higher temporal resolution has been boosted in the very recent year by the development of free-electron lasers (FEL) [34-36]. In FEL facilities, ultrashort pulses of X-rays paved the way for spectroscopic experiment in the femtosecond timescale [37-39]. This allowed for investigating the local electronic and structural modifications occurring in a transition metal compound immediately after the photoexcitation. For example, Bressler et al. used femtosecond XANES to solve a long-standing issue about the population mechanism of quintet states in iron(II)-based complexes, which resulted to be a ${ }^{1} \mathrm{MLCT} \rightarrow{ }^{3} \mathrm{MLCT} \rightarrow{ }^{5} \mathrm{~T}$ cascade from the initially excited state [29].

In the field of semiconducting oxides, Santomauro and co-workers extended the investigation of Ritmann et al. by performing the XAS experiment at an XFEL facility to probe the dynamics of the trapping of the photogenerated electrons in $\mathrm{TiO}_{2}$ [40]. They concluded that the electrons are localized in correspondence of $\mathrm{Ti}$ atoms in a time lower than $300 \mathrm{fs}$, leading to the formation of $\mathrm{Ti}^{3+}$ centers. In addition, they confirmed that electrons are localized at Ti penta-coordinate sites.

The dynamics of the photoexcitation was also investigated at an XFEL in the case of $\mathrm{WO}_{3}$ nanoparticles. Uemura et al. observed that immediately after the excitation the tungsten is initially reduced from $\mathrm{W}(\mathrm{VI})$ to a mean oxidation state of 5.3 [38]. Subsequently, the tungsten oxide undergoes a change in its local structure within the following $200 \mathrm{ps}$. Some of the results of this paper are reported in Figure 5. 

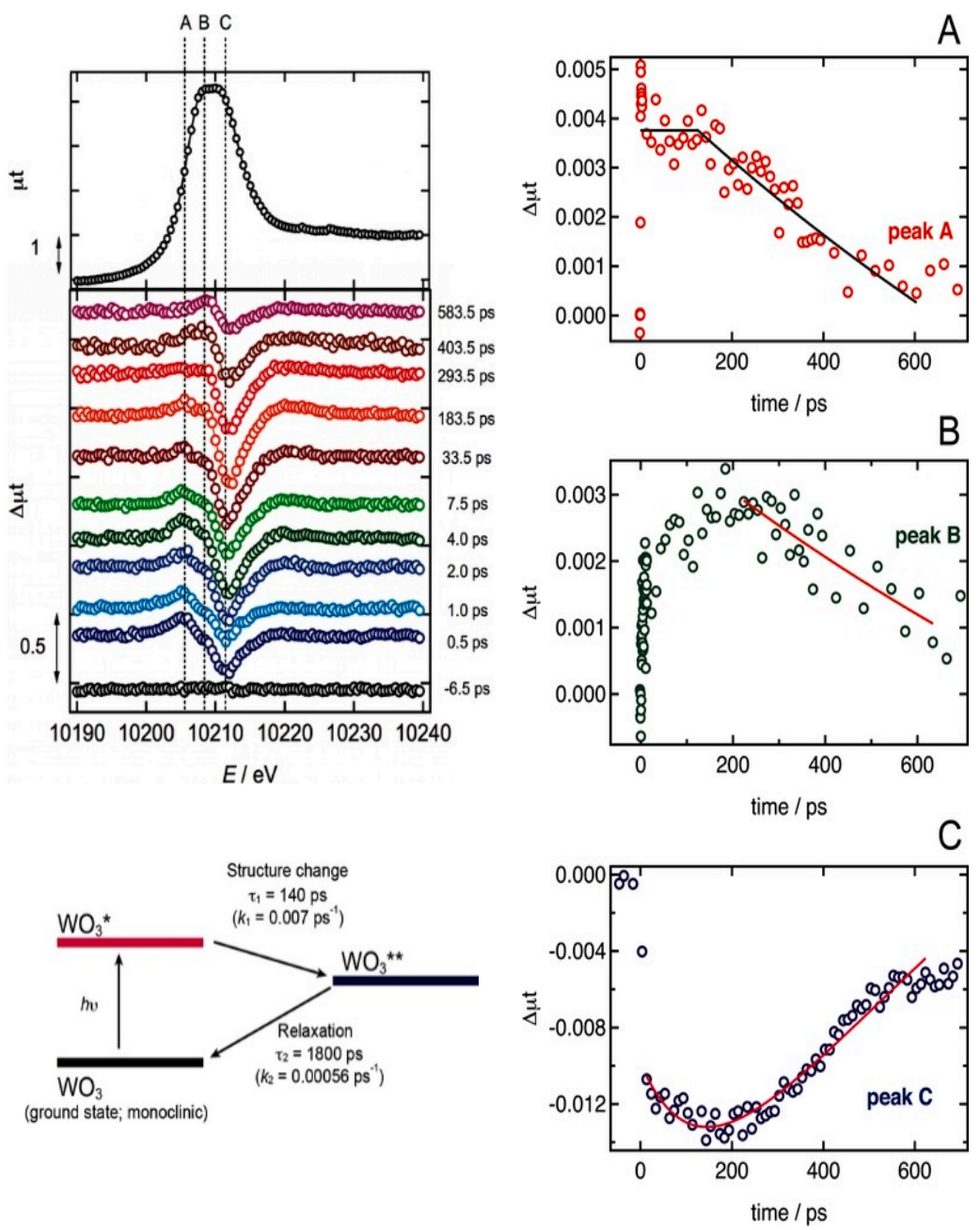

Figure 5. Top, left: $\mathrm{W} \mathrm{L}_{\mathrm{III}}$ XANES spectra of WO3 in the ground state together with differential XANES spectra of $\mathrm{WO}_{3}$, each being the subtraction of the XANES spectrum of an excited state (at the indicated time) and the spectrum of a ground state. Right: Absorption intensities of $W \mathrm{~L}_{\mathrm{III}}$ XANES for peaks A, $B$, and $C$ (as shown in the figure at the left) as a function of time. Bottom, left: A proposed scheme for the photoexcitation process of $\mathrm{WO}_{3}$. Reprinted from [38]. Copyright 2016, with permission from Wiley.

All the listed cases refer to ex-situ or in-situ (on solvent dispersed particles) experiments, where, in most cases, the semiconductors or the complexes are photoexcited and the dynamics of the photogenerated carriers is followed. As a matter of fact, pump \& probe XAS, either at synchrotron or at FEL facilities, is still in its very early days, to the point that studies under operando condition are very rare, and are mainly obtained by adding a sacrificial donor or acceptor and not by applying an external potential. In fact, to the authors' best knowledge, only one contribution was published, limited to synchrotron radiation pump \& probe XAS [41].

In this work, the authors investigated the $\alpha-\mathrm{Fe}_{2} \mathrm{O}_{3} / \mathrm{IrO}_{\mathrm{x}}$ architecture as a model photoelectrode, and they could detect a charge transfer between hematite and $\mathrm{IrO}_{\mathrm{x}}$ occurring in the nanosecond timescale, resulting in reduction of Ir or in an increased density of empty Ir $5 d$ states depending on the applied potential. Figure 6 represents schematically the adopted setup (left) together with the results obtained when an anodic photocurrent is observed. In this case, difference spectra indicate a hole transfer from the semiconductor to $\mathrm{IrO}_{\mathrm{x}}$ when no delay between pump \& probe is applied. When pump \& probe are delayed for $600 \mathrm{~ns}$, the Ir $5 d$ state results to be depleted, indicating a more intense hole transfer. 

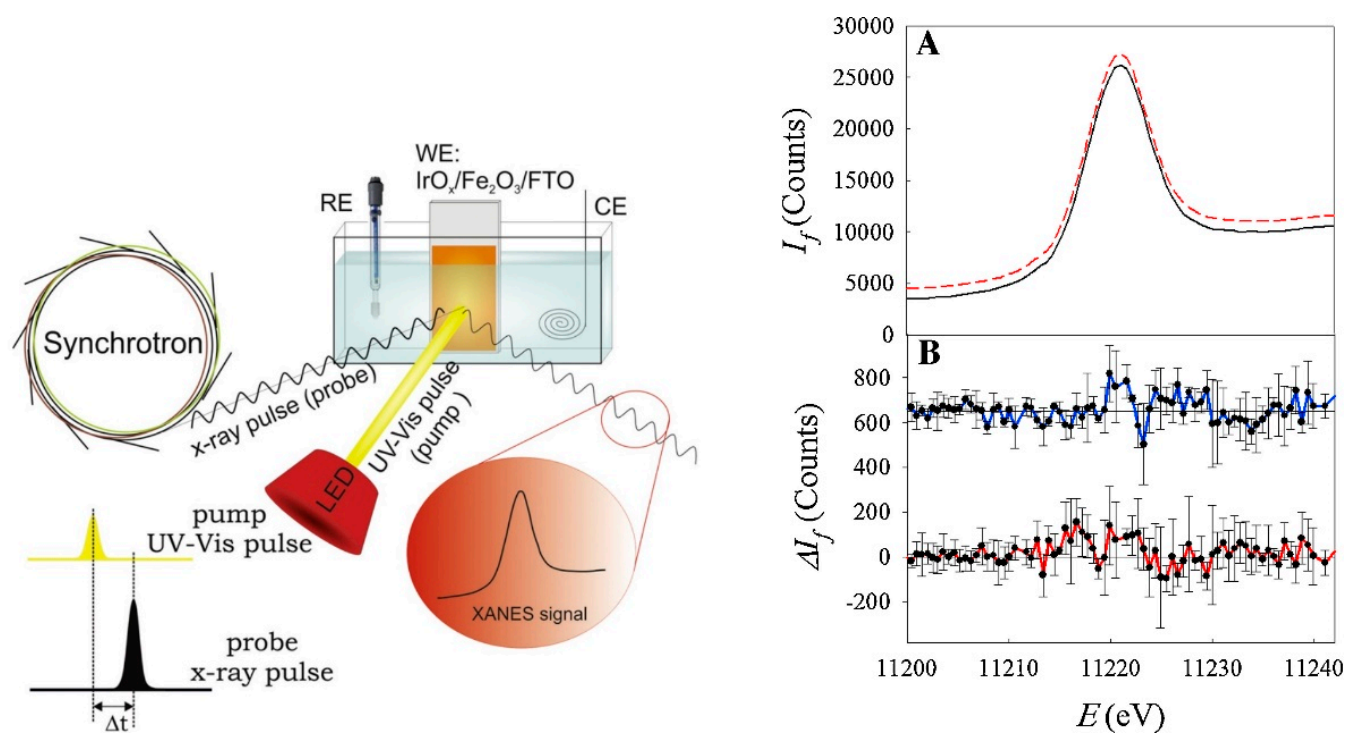

Figure 6. Left: schematic setup for an operando pump \& probe ( $\mathrm{P} \& \mathrm{P})$ experiment on a photoelectrochemical system using synchrotron light. The UV-Vis pump is synchronized with the probe pulses, the latter generated by single bunches from the synchrotron. Right: (A) Ir- $\mathrm{L}_{\text {III }}$ XANES spectrum in the presence (red dotted line) and in the absence (black full line) of $400 \mathrm{~nm}$ light acquired in presence of $600 \mathrm{~ns}$ delay between the pump and the probe; spectra are shifted along the y axis for the sake of better clarity. (B) difference spectra (light on-light off, with error bars) in the presence (red line) and in the absence (blue line) of delay; the two spectra are shifted for clarity, and the zero is defined by black horizontal lines. Reprinted from [41]. Copyright 2016, with permission from Elsevier.

\section{FEXRAV}

Finally, an alternative approach is to fix the X-ray energy and record the corresponding absorption coefficient as a function of time. In this case, in the framework of hyphenated techniques, it would be convenient to collect joint information from electrochemical methods. This is the principle behind the fixed energy X-ray absorption voltammetry (FEXRAV). This technique is an application of the single energy $X$-ray absorption detection first proposed by Filipponi et al. [42]. It consists in recording the X-ray absorption coefficient at a fixed energy while the applied potential in an electrochemical cell is scanned according to a cyclic voltammetry triangular-wave program [43]. If the energy is properly selected to give the maximum contrast between the spectral features of different oxidation states, any shift from the original oxidation state determines a variation of the absorption coefficient, and can then be detected. FEXRAV allows for quickly mapping the oxidation states of the element under consideration within the selected potential window, and this can be preliminary to deeper X-ray absorption spectroscopy (XAS) characterizations, like XANES or EXAFS. Moreover, the time-length of the experiment is much shorter than a series of XAS spectra and opens the door to kinetic analysis. Initially introduced for the study of $\mathrm{IrO}_{x}$ materials, FEXRAV has been applied to operando studies of the electrochemistry of a variety of materials, from Ag nanoparticles [44], to copper oxide materials [45], to iron oxide and oxo-hydroxide materials [46], to palladium based electrocatalysts [47]. Figure 7 reports an example of a FEXRAV experiment in the case of Ag nanoparticles studied as electrocatalysts for the electrodehalogenation of trichloromethane in aqueous media. Here the X-ray energy is set at a value that guarantees the increase of $\mu$ when $\mathrm{Ag}$ is oxidized. The potential is swept from 0 to $-1.1 \mathrm{~V}$ and there's a visible decrease of $\mu$ due to the presence (adsorption) of trichloromethane or of its reduction intermediates. The release of $\mathrm{Cl}^{-}$causes $\mathrm{Ag}$ to oxidize at about $0.2 \mathrm{~V}$. This is witnessed by XAS, by means of an increase of $\mu$. The latter decreases when the potential is reversed, in correspondence to the reduction peak at about $0.1 \mathrm{~V}$. 


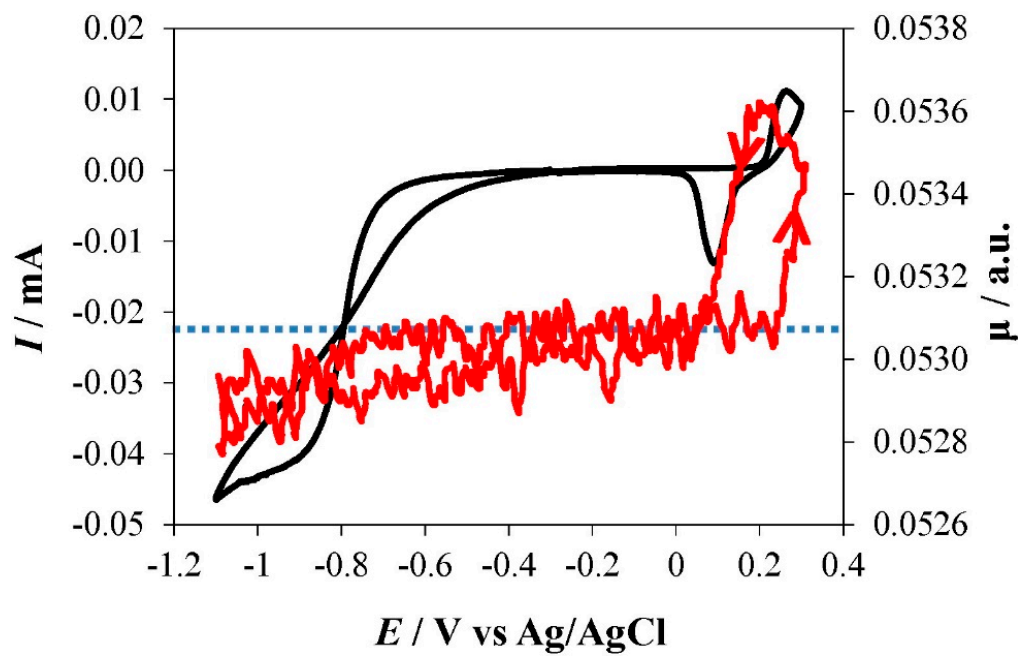

Figure 7. Example of a fixed energy X-ray absorption voltammetry experiment on Ag nanoparticles in aqueous of $10 \mathrm{mM}$ trichloromethane (chloroform): CV (black) and FEXRAV (red) at $1 \mathrm{mV} \cdot \mathrm{s}^{-1}$. Reprinted from [44]. Copyright 2016, with permission from Elsevier.

\section{Conclusions and Perspectives}

This minireview aims at providing a comprehensive and updated overview of the state of the art concerning use and capabilities of time resolved XAS in electrochemistry and photoelectrochemistry.

It is evident that the number of published papers on these topics is not very large, especially if compared to other types of spectroscopies. This is due to two main factors: (i) the dependence on large facilities, which limits the number of users that can approach and that have access to these techniques; (ii) the general unawareness to electrochemists of the mere existence of XAS, notwithstanding its very high potentialities. Of course, these two factors are strongly related.

Indeed, as we hope to have successfully demonstrated in this work, the potentialities of time resolved XAS are very high. In fact, time resolved XAS can help to clarify reaction mechanisms, metastable (transient) structures and to identify the nature of intermediate reacting states, and we hope that the range of applications will extend progressively in the close future.

Fortunately, we are witnessing a progressive increase of available synchrotron radiation sources (for a general outlook at the existing facilities, the reader is referred to the website https:/ /lightsources. org/lightsources-of-the-world/). In parallel, it is worth noting that innovative benchtop laboratory $X$-ray spectrophotometers are commercially available. Even if the photon flux of these instruments is still not comparable with that available at a synchrotron beamline, we believe that technical advances will allow for rapid improvements which, together with an increasing knowledge on the correct design of samples and cells [48], will likely make XAS available also in academics and companies worldwide.

Funding: A.M. is thankful to Università degli Studi di Milano through the "Piano di Sostegno alla Ricerca 2015/2017".

Conflicts of Interest: The authors declare no conflict of interest.

\section{References}

1. Simpson, B.H.; Rodríguez-López, J. Emerging techniques for the in situ analysis of reaction intermediates on photo-electrochemical interfaces. Anal. Methods 2015, 7, 7029-7041. [CrossRef]

2. Caudillo-Flores, U.; Muñoz-Batista, M.J.; Kubacka, A.; Fernández-García, M. Operando Spectroscopy in Photocatalysis. Chem. Photo Chem. 2018, 777-785.

3. Minguzzi, A.; Ghigna, P. X-ray absorption spectroscopy in electrochemistry from fundamentals to fixed energy X-ray absorption voltammetry. In Electroanalytical Chemistry: A Series of Advances, Volume 27; Bard, A.J., Zoski, C.G., Eds.; CRC Press-Taylor and Francis Group: Boca Raton, FL, USA, 2017; pp. 119-181, ISBN 9781351981675. 
4. Russell, A.E.; Rose, A. X-ray absorption spectroscopy of low temperature fuel cell catalysts. Chem. Rev. 2004, 104, 4613-4635. [CrossRef]

5. Abruña, H.D.; Bommarito, G.M.; Yee, H.S. X-ray Standing Waves and Surface EXAFS Studies of Electrochemical Interfaces. Acc. Chem. Res. 1995, 28, 273-279. [CrossRef]

6. Sharpe, L.R.; Heineman, W.R.; Elder, R.C. EXAFS Spectroelectrochemistry. Chem. Rev. 1990, 90, 705-722. [CrossRef]

7. Doyle, R.L.; Godwin, I.J.; Brandon, M.P.; Lyons, M.E.G. Redox and electrochemical water splitting catalytic properties of hydrated metal oxide modified electrodes. Phys. Chem. Chem. Phys. 2013, 15, 13737-13783. [CrossRef] [PubMed]

8. Frahm, R. Quick scanning exafs: First experiments. Nucl. Inst. Methods Phys. Res. A 1988, 270, 578-581. [CrossRef]

9. Frahm, R. New method for time dependent X-ray absorption studies. Rev. Sci. Instrum. 1989, 60, $2515-2518$. [CrossRef]

10. Stötzel, J.; Lützenkirchen-Hecht, D.; Frahm, R. A new flexible monochromator setup for quick scanning X-ray absorption spectroscopy. Rev. Sci. Instrum. 2010, 81, 073109. [CrossRef]

11. Müller, O.; Nachtegaal, M.; Just, J.; Lützenkirchen-Hecht, D.; Frahm, R. Quick-EXAFS setup at the SuperXAS beamline for in situ X-ray absorption spectroscopy with 10ms time resolution. J. Synchrotron Radiat. 2016, 23, 260-266. [CrossRef]

12. Yu, X.; Wang, Q.; Zhou, Y.; Li, H.; Yang, X.Q.; Nam, K.W.; Ehrlich, S.N.; Khalid, S.; Meng, Y.S. High rate delithiation behaviour of LiFePO4studied by quick X-ray absorption spectroscopy. Chem. Commun. 2012, 48, 11537-11539. [CrossRef]

13. Ishiguro, N.; Saida, T.; Uruga, T.; Nagamatsu, S.I.; Sekizawa, O.; Nitta, K.; Yamamoto, T.; Ohkoshi, S.I.; Iwasawa, Y.; Yokoyama, T.; et al. Operando time-resolved X-ray absorption fine structure study for surface events on a $\mathrm{Pt} 3 \mathrm{Co} / \mathrm{C}$ cathode catalyst in a polymer electrolyte fuel cell during voltage-operating processes. ACS Catal. 2012, 2, 1319-1330. [CrossRef]

14. Gorlin, Y.; Lassalle-Kaiser, B.; Benck, J.D.; Gul, S.; Webb, S.M.; Yachandra, V.K.; Yano, J.; Jaramillo, T.F. In situ $\mathrm{X}$-ray absorption spectroscopy investigation of a bifunctional manganese oxide catalyst with high activity for electrochemical water oxidation and oxygen reduction. J. Am. Chem. Soc. 2013, 135, 8525-8534. [CrossRef] [PubMed]

15. Allen, P.G.; Conradson, S.D.; Wilson, M.S.; Gottesfeld, S.; Raistrick, I.D.; Valerio, J.; Lovato, M. Direct observation of surface oxide formation and reduction on platinum clusters by time-resolved X-ray absorption spectroscopy. J. Electroanal. Chem. 1995, 384, 99-103. [CrossRef]

16. McBreen, J.; O'Grady, W.E.; Tourillon, G.; Dartyge, E.; Fontaine, A.; Pandya, K.I. In situ time-resolved X-ray absorption near edge structure study of the nickel oxide electrode. J. Phys. Chem. 1989, 93, 6308-6311. [CrossRef]

17. Dent, A.; Evans, J.; Newton, M.; Corker, J.; Russell, A.; Abdul Rahman, M.B.; Fiddy, S.; Mathew, R.; Farrow, R.; Salvini, G.; et al. High-quality energy-dispersive XAFS on the $1 \mathrm{~s}$ timescale applied to electrochemical and catalyst systems. J. Synchrotron Radiat. 1999, 6, 381-383. [CrossRef] [PubMed]

18. Pascarelli, S.; Mathon, O.; Muñoz, M.; Mairs, T.; Susini, J. Energy-dispersive absorption spectroscopy for hard-X-ray micro-XAS applications. J. Synchrotron Radiat. 2006, 13, 351-358. [CrossRef] [PubMed]

19. Labiche, J.-C.; Mathon, O.; Pascarelli, S.; Newton, M.A.; Ferre, G.G.; Curfs, C.; Vaughan, G.B.M.; Homs, A.; Carreiras, D.F. The fast readout low noise camera as a versatile $\mathrm{X}$-ray detector for time resolved dispersive extended X-ray absorption fine structure and diffraction studies of dynamic problems in materials science, chemistry, and catalysis. Rev. Sci. Instrum. 2007, 78, 91301. [CrossRef] [PubMed]

20. Pascarelli, S.; Mathon, O. Advances in high brilliance energy dispersive X-ray absorption spectroscopy. Phys. Chem. Chem. Phys. 2010, 12, 5535-5546. [CrossRef]

21. Rose, A.; South, O.; Harvey, I.; Diaz-Moreno, S.; Owen, J.R.; Russell, A.E. In situ time resolved studies of hydride and deuteride formation in $\mathrm{Pd} / \mathrm{C}$ electrodes via energy dispersive $\mathrm{X}$-ray absorption spectroscopy. Phys. Chem. Chem. Phys. 2005, 7, 366-372. [CrossRef]

22. O'Malley, R.; Vollmer, A.; Lee, J.; Harvey, I.; Headspith, J.; Diaz-Moreno, S.; Rayment, T. Time-resolved studies of diffusion via energy dispersive X-ray absorption spectroscopy. Electrochem. commun. 2003, 5, 1-5. [CrossRef] 
23. Allen, P.G.; Conradson, S.D.; Wilson, M.S.; Gottesfeld, S.; Raistrick, I.D.; Valerio, J.; Lovato, M. In situ structural characterization of a platinum electrocatalyst by dispersive X-ray absorption spectroscopy. Electrochim. Acta 1994, 39, 2415-2418. [CrossRef]

24. Imai, H.; Izumi, K.; Matsumoto, M.; Kubo, Y.; Kato, K.; Imai, Y. In Situ and Real-Time Monitoring of Oxide Growth in a Few Monolayers at Surfaces of Platinum Nanoparticles in Aqueous Media In Situ and Real-Time Monitoring of Oxide Growth in a Few Monolayers at Surfaces of Platinum Nanoparticles in Aqueous. J. Am. Chem. Soc. 2009, 131, 6293-6300. [CrossRef] [PubMed]

25. Minguzzi, A.; Montagna, L.; Falqui, A.; Vertova, A.; Rondinini, S.; Ghigna, P. Dynamics of oxide growth on $\mathrm{Pt}$ nanoparticles electrodes in the presence of competing halides by operando energy dispersive $\mathrm{X}$-ray absorption spectroscopy. Electrochim. Acta 2018, 270, 378-386. [CrossRef]

26. Zolfaghari, A.; Conway, B.E.; Jerkiewicz, G. Elucidation of the effects of competitive adsorption of Cl-and Brions on the initial stages of $\mathrm{Pt}$ surface oxidation by means of electrochemical nanogravimetry. Electrochim. Acta 2002, 47, 1173-1187. [CrossRef]

27. Rondinini, S.; Minguzzi, A.; Achilli, E.; Locatelli, C.; Agostini, G.; Spinolo, G.; Vertova, A.; Ghigna, P. The dynamics of pseudocapacitive phenomena studied by Energy Dispersive XAS on hydrous iridium oxide electrodes in alkaline media. Electrochim. Acta 2016, 212, 247-253. [CrossRef]

28. Achilli, E.; Vertova, A.; Visibile, A.; Locatelli, C.; Minguzzi, A.; Rondinini, S.; Ghigna, P. Structure and Stability of a Copper(II) Lactate Complex in Alkaline Solution: A Case Study by Energy-Dispersive X-ray Absorption Spectroscopy. Inorg. Chem. 2017, 56. [CrossRef] [PubMed]

29. Bressler, C.; Milne, C.; Pham, V.-T.; Elnahhas, A.; van der Veen, R.M.; Gawelda, W.; Johnson, S.; Beaud, P.; Grolimund, D.; Kaiser, M.; Borca, C.N.; et al. Femtosecond XANES study of the light-induced spin crossover dynamics in an iron(II) complex. Science 2009, 323, 489-492. [CrossRef]

30. Rittmann-Frank, M.H.; Milne, C.J.; Rittmann, J.; Reinhard, M.; Penfold, T.J.; Chergui, M. Mapping of the photoinduced electron traps in $\mathrm{TiO} 2$ by picosecond X-ray absorption spectroscopy. Angew. Chem. Int. Ed. 2014, 53, 5858-5862. [CrossRef] [PubMed]

31. Song, F.; Moré, R.; Schilling, M.; Smolentsev, G.; Azzaroli, N.; Fox, T.; Luber, S.; Patzke, G.R. \{Co4O4\} and \{CoxNi4-xO4\} Cubane Water Oxidation Catalysts as Surface Cut-Outs of Cobalt Oxides. J. Am. Chem. Soc. 2017, 139, 14198-14208. [CrossRef]

32. Moonshiram, D.; Gimbert-Suriñach, C.; Guda, A.; Picon, A.; Lehmann, C.S.; Zhang, X.; Doumy, G.; March, A.M.; Benet-Buchholz, J.; Soldatov, A.; et al. Tracking the Structural and Electronic Configurations of a Cobalt Proton Reduction Catalyst in Water. J. Am. Chem. Soc. 2016, 138, 10586-10596. [CrossRef] [PubMed]

33. Canton, S.E.; Zhang, X.; Liu, Y.; Zhang, J.; Pápai, M.; Corani, A.; Smeigh, A.L.; Smolentsev, G.; Attenkofer, K.; Jennings, G.; et al. Watching the dynamics of electrons and atoms at work in solar energy conversion. Faraday Discuss. 2015, 185, 51-68. [CrossRef] [PubMed]

34. Chergui, M. Emerging photon technologies for chemical dynamics. Faraday Discuss. 2014, 171, 11-40. [CrossRef] [PubMed]

35. Patterson, B.D.; Abela, R. Novel opportunities for time-resolved absorption spectroscopy at the X-ray free electron laser. Phys. Chem. Chem. Phys. 2010, 12, 5647-5652. [CrossRef] [PubMed]

36. Lemke, H.T.; Bressler, C.; Chen, L.X.; Fritz, D.M.; Gaffney, K.J.; Galler, A.; Gawelda, W.; Haldrup, K.; Hartsock, R.W.; Ihee, H.; et al. Femtosecond X-ray absorption spectroscopy at a hard X-ray free electron laser: Application to spin crossover dynamics. J. Phys. Chem. A 2013, 117, 735-740. [CrossRef] [PubMed]

37. Oloff, L.P.; Chainani, A.; Matsunami, M.; Takahashi, K.; Togashi, T.; Osawa, H.; Hanff, K.; Quer, A.; Matsushita, R.; Shiraishi, R.; et al. Time-resolved HAXPES using a microfocused XFEL beam: From vacuum space-charge effects to intrinsic charge-carrier recombination dynamics. Sci. Rep. 2016, 6, 1-10. [CrossRef] [PubMed]

38. Uemura, Y.; Kido, D.; Wakisaka, Y.; Uehara, H.; Ohba, T.; Niwa, Y.; Nozawa, S.; Sato, T.; Ichiyanagi, K.; Fukaya, R.; et al. Dynamics of Photoelectrons and Structural Changes of Tungsten Trioxide Observed by Femtosecond Transient XAFS. Angew. Chemie Int. Ed. 2016, 55, 1364-1367. [CrossRef] [PubMed]

39. Picón, A.; Lehmann, C.S.; Bostedt, C.; Rudenko, A.; Marinelli, A.; Osipov, T.; Rolles, D.; Berrah, N.; Bomme, C.; Bucher, M.; et al. Hetero-site-specific X-ray pump-probe spectroscopy for femtosecond intramolecular dynamics. Nat. Commun. 2016, 7, 5-10. [CrossRef] 
40. Santomauro, F.G.; Lübcke, A.; Rittmann, J.; Baldini, E.; Ferrer, A.; Silatani, M.; Zimmermann, P.; Grübel, S.; Johnson, J.A.; Mariager, S.O.; et al. Femtosecond X-ray absorption study of electron localization in photoexcited anatase TiO2. Sci. Rep. 2015, 5, 14834. [CrossRef]

41. Baran, T.; Fracchia, M.; Vertova, A.; Achilli, E.; Naldoni, A.; Malara, F.; Rossi, G.; Rondinini, S.; Ghigna, P.; Minguzzi, A.; et al. Operando and Time-Resolved X-ray Absorption Spectroscopy for the Study of Photoelectrode Architectures. Electrochim. Acta 2016, 207, 16-21. [CrossRef]

42. Filipponi, A.; Borowski, M.; Loeffen, P.W.; De Panfilis, S.; Di Cicco, A.; Sperandini, F.; Minicucci, M.; Giorgetti, M. Single-energy X-ray absorption detection: A combined electronic and structural local probe for phase transitions in condensed matter. J. Phys. Condens. Matter 1998, 10, 235-253. [CrossRef]

43. Minguzzi, A.; Lugaresi, O.; Locatelli, C.; Rondinini, S.; D'Acapito, F.; Achilli, E.; Ghigna, P. Fixed energy X-ray absorption voltammetry. Anal. Chem. 2013, 85, 7009-7013. [CrossRef] [PubMed]

44. Rondinini, S.; Lugaresi, O.; Achilli, E.; Locatelli, C.; Vertova, A.; Ghigna, P.; Minguzzi, A.; Comninellis, C. Fixed Energy X-ray Absorption Voltammetry and Extended X-ray Absorption Fine Structure of Ag Nanoparticle Electrodes. J. Electroanal. Chem. 2016, 766, 71-77. [CrossRef]

45. Baran, T.; Wojtyła, S.; Lenardi, C.; Vertova, A.; Ghigna, P.; Achilli, E.; Fracchia, M.; Rondinini, S.; Minguzzi, A. An Efficient CuxO Photocathode for Hydrogen Production at Neutral pH: New Insights from Combined Spectroscopy and Electrochemistry. ACS Appl. Mater. Interfaces 2016, 8, 21250-21260. [CrossRef] [PubMed]

46. Fracchia, M.; Visibile, A.; Ahlberg, E.; Vertova, A.; Minguzzi, A.; Ghigna, P.; Rondinini, S. $\alpha$ - and $\gamma$-FeOOH: Stability, Reversibility, and Nature of the Active Phase under Hydrogen Evolution. ACS Appl. Energy Mater. 2018, 1, 1716-1725. [CrossRef]

47. Montegrossi, G.; Giaccherini, A.; Berretti, E.; Di Benedetto, F.; Innocenti, M.; d'Acapito, F.; Lavacchi, A. Computational Speciation Models: A Tool for the Interpretation of Spectroelectrochemistry for Catalytic Layers under Operative Conditions. J. Electrochem. Soc. 2017, 164, E3690-E3695. [CrossRef]

48. Achilli, E.; Minguzzi, A.; Visibile, A.; Locatelli, C.; Vertova, A.; Naldoni, A.; Rondinini, S.; Auricchio, F.; Marconi, S.; Fracchia, M.; et al. 3D-printed photo-spectroelectrochemical devices for in situ and in operando X-ray absorption spectroscopy investigation. J. Synchrotron Radiat. 2016, 23, 622-628. [CrossRef] [PubMed]

(C) 2018 by the authors. Licensee MDPI, Basel, Switzerland. This article is an open access article distributed under the terms and conditions of the Creative Commons Attribution (CC BY) license (http:/ / creativecommons.org/licenses/by/4.0/). 